\title{
Large choroidal malignant melanoma presentıng as neovascular glaucoma
}

\author{
Berna SAHAN ${ }^{*}$, Samuray TUNCER ${ }^{2}$ and Ilgaz YALVAC ${ }^{1}$ \\ ${ }^{1}$ Department of Ophthalmology, Yeditepe University, Faculty of Medicine, Turkey \\ ${ }^{2}$ Department of Ophthalmology, Istanbul University, Istanbul Faculty of Medicine, Turkey
}

\begin{abstract}
Objectives: To report a patient with choroidal malignant melanoma presenting as neovascular glaucoma.

Patient and methods: We retrospectively reviewed medical history and diagnostic tests of a 64 year old male patient with uveal melanoma.

Results: A large mass was observed during our first examination and patient has been treated for neovascular glaucoma before admitting to our clinic. The huge mass, which filled the vitreous cavity, was detected by B-scan ultrasonography. Enuclation was performed and histopathologic analysis of enuclation material revealed uveal melanoma. Initially there was no evidence of metastasis. He was died due to liver metastasis of choroidal melanoma, six months later.

Conclusions: Choroidal melanoma can present as neovascular glaucoma in some patients. In suspicious conditions, choroidal melanoma should be considered in patients with neovascular glaucoma.
\end{abstract}

\section{Introduction}

Neovascular glaucoma is caused by tissue hypoxia, especially secondary to posterior segment diseases. Angiogenic factors precipitate neovascularization in trabecular meshwork. Due to this, aqueus outflow is obtructed and intraocular pressure is increased. The most common reasons of neovascular glaucoma are diabetic retinopathy, central retinal vein occlusion and ocular ischemic syndrome. Another etiological reason is ocular tumors such as malign melonoma (MM).

Malign melonoma is a very dangerous malignancy and rarely seen in the eye. Uveal melanoma involves the choroid (90\%), ciliary body (6\%) and iris (4\%) [1]. Incidence of choroidal melanoma is 4,9 per million in US, 8 per million in Northern Europe and 2 per million in southern Europe [2,3].

Herein, we report a case of uveal malign melonoma presenting as neovascular glaucoma.

\section{Case}

A 64 year old male patient referred to our clinic with a pre-diagnosis of neovascular glaucoma in his left eye (LE). He presented with pain, redness and decreased vision in his LE 2 months ago. There was no history of diabetes mellitus and tobacco use. On ophthalmological examination, visual acuity was 0.7 (Snellen) in right eye and light perception in LE. Intraocular pressure was $12 \mathrm{mmHg}$ in right eye and $35 \mathrm{mmHg}$ while using beta blocker/carbonic anhydrase inhibitor combination, prostaglandin analog and alpha- 2 agonist in the LE. Conjuctival hyperemia, neovascularization of iris and a huge mass extending to anterior vitreous were observed on slit-lamp examination (Figure 1). B-scan ultrasonography showed the mass which fully filled the vitreous cavity. Enuclation of the left eye was performed by ophthalmic oncologist. On macroscopic examination of the specimen, tumor was pigmented and the size of tumor was $2.3 \times 1.6 \mathrm{~cm}$. On microscopic examination, there were pleomorphic, atypical fusiform cells. The final pathology was type A choroidal malign melanoma (Figure 2). No metastasis was detected by imaging methods for tumor metastasis, at that time. He followed with these findings and the general condition of the patient progresivelly worsened. He was died due to liver metastasis of choroidal melanoma, six months later.

\section{Discussion}

Uveal melanoma is the most common primary intraocular tumor in adults originating from melanocytes located in iris, ciliary body and choroid [4]. Incidence of choroidal melanoma is 4,9 per million in US, 8 per million in Northern Europeand 2 per million in southern Europe

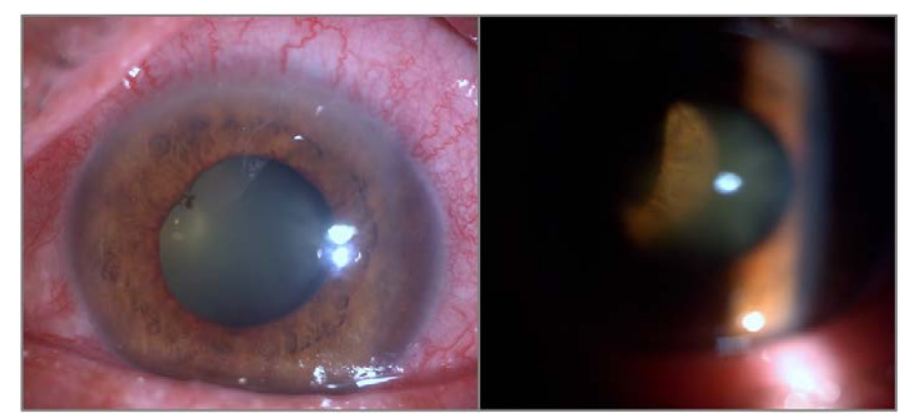

Figure 1. Conjuctival hyperemia, neovascularization of iris and a huge mass extending to anterior vitreous.

Correspondence to: Berna SAHAN, Sakir Kesebir Sokak No:28, BalmumcuBesiktas, Istanbul, Turkey, Tel: +90 21221140 00; Fax: +90 21221125 00; E-mail: gokceberna@hotmail.com

Key words: choroidal melanoma, neovascular glaucoma, secondary glaucoma, ultrasonograhy, enuclation, liver metastasis

Received: March 28, 2017; Accepted: April 21, 2017; Published: April 24, 2017 


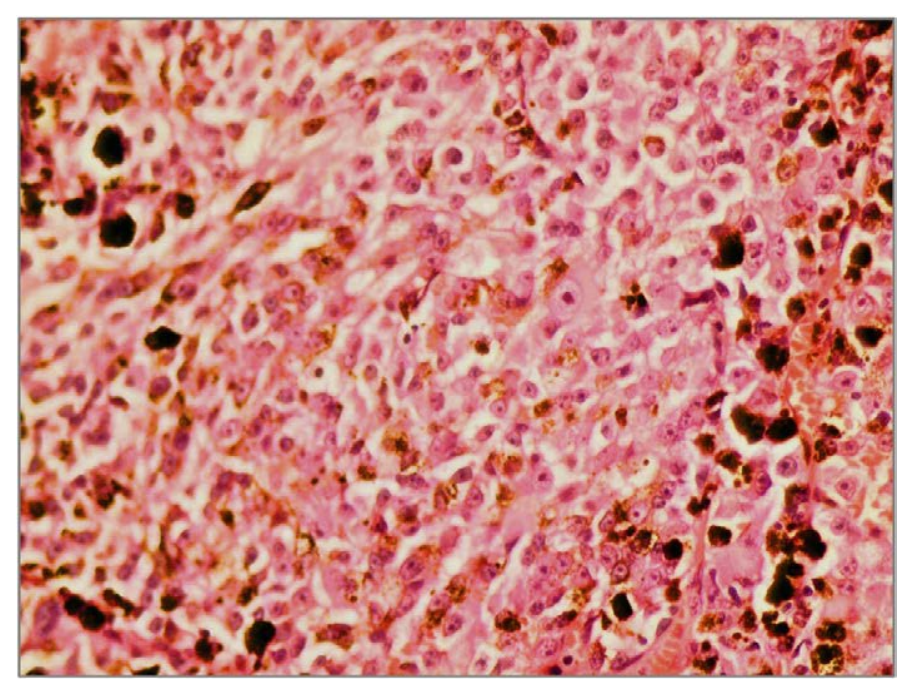

Figure 2. The pathological specimen shows the choroidal malign melanoma type A spindle cells.

$[2,3]$. Choroid is the most frequently effected area by uveal melanoma (90\%) [1]. However, cancer metastasis such as metastasis of small cell lung cancer is the most common cause of choroidal tumors [5].

Symptoms of uveal melanoma includes blurred vision, visual field defects, photopsia, floaters and pain but at the time of diagnosis $30 \%$ of patients could be asymptomatic [6]. Choroidal melanoma usually appears as a pigmented, dome shaped mass in fundus examination. The other clinical features are retinal detachments, vitreous hemorrhages and secondary glaucoma [1]. Secondary glaucoma may appear before and after the diagnosis of choroidal melanoma. In this case, neovascular glaucoma was the initial manifestation of choroidal melanoma. Before admission to our clinic, physicians in an outer center who started to treat neovascular glaucoma with drops, did not notice the choroidal mass. In our examination, the huge mass extending to anterior vitreous was evaluated in slit lamp examination.
In addition to clinical examination, B-scan ultrasonography (USG), fundus flourescein angiography, indocyanin green angiography, enhanced depth optical coherence tomography, autofluoresence, fineneedle aspiration biopsy, cytogenetic analysis use for diagnosis of uveal melanoma [1]. B-scan USG is easily accessible and very useful device for the diagnosis of uveal tumours. In this case, the tumor was evaluated by B-scan ultrasonograhy after fundus examination. Vitreous cavity was filled with tumor in the B-scan ultrasonography.

Plaque radiotherapy and enuclation are the most common treatment options in patients with uveal melanoma [4]. Enuclation was perfomed by ophthalmic oncologist and the pathology of the tumor was type-A choroidal melanoma.

Neovascular glaucoma may be the first clinical feature of choroidal melonoma. Ethiology of neovascular glaucoma must be investigated carefully and choroidal melanoma should not be missed in cases with suspicious conditions.

\section{References}

1. Shields CL, Manalac J, Das C, Ferguson K, Shields JA (2014) Choroidal melanoma: clinical features, classification, and top 10 pseudomelanomas. Curr Opin Ophthalmol 25: 177-185. [Crossref]

2. McLaughlin CC, Wu XC, Jemal A, Martin HJ, Roche LM, et al. (2005) Incidence of noncutaneous melanomas in the U.S. Cancer 103: 1000-1007. [Crossref]

3. Virgili G, Gatta G, Ciccolallo L, Capocaccia R, Biggeri A, et al. (2007) Incidence of uveal melanoma in Europe. Ophthalmology 114: 2309-2315. [Crossref]

4. Jovanovic P, Mihajlovic M, Djordjevic-Jocic J, Vlajkovic S, Cekic S, et al. (2013) Ocular melanoma: an overview of the current status. Int J Clin Exp Pathol 6: 12301244. [Crossref]

5. Shah CP, Shienbaum G, Shields CL, Eagle RC, Lally S, et al. (2011) Neovascular glaucoma as the presenting sign of metastatic small cell lung carcinoma. Retin Cases Brief Rep 5: 26-29. [Crossref]

6. Damato EM, Damato BE (2012) Detection and time to treatment of uveal melanoma in the United Kingdom: an evaluation of 2,384 patients. Ophthalmology 119: 1582-1589. [Crossref]

Copyright: (C2017 Berna SAHAN. This is an open-access article distributed under the terms of the Creative Commons Attribution License, which permits unrestricted use, distribution, and reproduction in any medium, provided the original author and source are credited. 